\title{
"DE BÁRBAROS Y SALVAJES". LA GUERRA DE CASTAS DE LOS MAYAS YUCATECOS SEGÚN LA PRENSA DE LA CIUDAD DE MÉXICO. 1877-1880
}

\author{
Jesús GuZmán Urióstegui \\ Maestría en Historia de México, fFyl, unam
}

\begin{abstract}
Resumen: Decididos a proteger sus tierras y su forma de vida, en 1847 los mayas yucatecos se levantaron en armas contra la llamada población blanca del estado. La prensa de la capital nacional no tardó mucho en enterarse del caso y darlo a conocer, asumiendo desde un principio una postura crítica en contra de los rebeldes, al considerarlos como enemigos del orden y el progreso, y por ende carentes de todo derecho social y político, incluido el de su propia existencia como raza. Para algunos, no había más que exterminarlos mediante la violencia; para otros, la mejor opción era la de su integración por medio de la educación y el trabajo. Durante el largo enfrentamiento, esta última postura tomó auge sobre todo a partir de 1877 . tras la asunción de Porfirio Díaz al poder, quien buscó implantar la paz como el fundamento para llevar al país al selecto grupo de las naciones civilizadas del mundo. El indígena como tal estorbaba para ello, pues se le creía perezoso, indolente y bárbaro. Por lo mismo, adujeron diversos periodistas, no había otra solución que integrarlo a la sociedad mexicana por el camino de su transformación radical, convirtiéndolo no tanto en un ciudadano de primera, sino en un ente dispuesto a las labores productivas; es decir, convirtiéndolo en mano de obra disponible, supuestamente libre.
\end{abstract}

Pal.abras a.ave: Guerra de Castas, mayas, prensa, Porfirio Díaz, paz, orden, progreso, integración, educación, trabajo.

Arstract: With a deep commitment to defend its lands and way of living, in 1847 the Mayas from Yucatán decided to take up arms against the white population in the State. The media from the capital spread the news criticizing the rebel group attitudes and cataloged them as enemies of order and progress, lacking of any political or social rights, even the right to exist as a specific race. The public opinion was divided. Some people thought that the solution was an ethnic cleansing; on the other side, the solution was to integrate them through education and work. While the confrontation was taking place the last opinion got stronger, especially in 1877 when Porfirio Díaz came to power and looked for a peaceful solution as a mean to be admitted on the group of the civilized countries of the world. The indigenous community was a hindrance for achieving this goal because of the common thought of the native as lazy. indolent and barbarous. Considering this status, as many journalist pointed out, the only solution was to integrate them to Mexican society with a drastic change, not turning them into a first class citizen but a productive being, meaning a kind of workforce available in any time, supposedly free.

Krywords: Caste war, Mayas, press, Porfirio Diaz, peace, order, progress, integration, education, work.

RECEPCón: 9 de enero de 2009.

Acriptacón: 31 de mayo de 2009. 



\title{
"DE BÁRBAROS Y SALVAJES". LA GUERRA DE CASTAS DE LOS MAYAS YUCATECOS SEGÚN LA PRENSA DE LA CIUDAD DE MÉXICO. 1877-1880
}

\author{
Jesús Guzmán Urióstegul \\ Maestría en Historia de México, ffyl, unam
}

\section{a) Antecedentes}

Cuando llegaron a la ciudad de México las noticias de la rebelión maya yucateca iniciada a mediados de 1847 , la prensa capitalina no dudó en considerarla de inmediato como un suceso extraordinario que, de no detenerse a tiempo, desembocaría en una verdadera guerra racial, misma que amenazaría de muerte a todos los elementos de vida e industria de la región: los blancos.

Con un poco de más calma, las opiniones empezaron a dividirse, no tanto en torno al análisis de las causas de la guerra, ni tampoco en el sentido de que si verdaderamente se trataba de una guerra de castas o no, ${ }^{1}$ sino en cuanto a los métodos que había que implementar para darle fin. Periódicos como El Globo, El Universal, y El Siglo Diez y Nueve exigían que se levantaran cuerpos de ejército dedicados exclusivamente al exterminio de los rebeldes, sin mediar tregua, ya por atentar éstos contra la paz social, ya por ser verdaderos traidores a la patria, pues se atrevían a perseguir fines "perversos" cuando la nación se encontraba en riesgo de sucumbir ante el avance de las tropas norteamericanas. Otros, como El Monitor Republicano, optaban por una salida negociada, dándole énfasis tanto al rigor, como a la benignidad y a toda otra providencia que tendiera a eliminar los motivos de desacuerdo de los mayas insurrectos. Reconocía, no obstante, que dicha salida negociada sería sólo una medida temporal, mientras se emprendía otra de mayores alcances, anhelada por muchos: la de la desaparición de la población indígena. Así, el miércoles 6 de junio de 1849 señaló al respecto:

Todas las personas sensatas convienen en la necesidad que hay de que desaparezca la raza indígena, numerosísima en nuestro país y la más atrasada por desgracia en la carrera de la civilización; mas no todos convenimos en los medios de hacerla des-

${ }^{1}$ Sobre las causas de la guerra, véase el sugestivo estudio de Robert Patch, "Descolonización, el problema agrario y los orígenes de la guerra de castas, 1812-1847", en Sociedad, estructura agraria y Estado en Yucatán. Mérida, Universidad Autónoma de Yucatán/ Universidad de Carolina del Norte/ Universidad de Texas/ Universidad de Alabama, 1990, pp. 45-95. 
aparecer. Pretendemos algunos, si no estamos engañados, en que para conseguir este fin, debe recurrirse a la violencia, a las armas; otros queremos hacer que se pierda esa raza civilizándola y mezclándola con las demás.

No han podido convencernos las razones alegadas por los sostenedores del primer medio, y si bien respetamos todas las opiniones, usando de la franqueza que hemos procurado sea nuestra divisa, repetiremos que ese arbitrio nos parece eminentemente inmoral e inhumano e indigno por lo mismo de un pueblo que profesa la libertad y el cristianismo. Bien sabemos que los que sostienen esas opiniones están animados de los mejores sentimientos, y que su error es hijo más bien de un raciocinio inexacto, que de un corazón perverso; por lo que no dudamos que prescindirán de sus ideas tan luego como reflexionando en ellas maduramente vean que no son conformes a la razón. ${ }^{2}$

Añadió dicho periódico que el exterminio por la vía de las armas no se justificaba, sobre todo porque lo primero que tenía que reconocerse era el olvido en que se tenía a los indígenas en general, a los que en muchas ocasiones no se les consideraba ni como parte del pueblo mexicano. Hijos del país sí, pero inferiores, segundones, sin derecho alguno debido a su falta de educación y su poca disposición al progreso.

Por lo mismo, continuó, para evitar consecuencias funestas, no había más que aplicar en el asunto dos clases de remedios. Unos lentos, pero radicales, como eran la propagación de las luces entre los miembros de esa raza, y la mezcla de ésta con los demás habitantes del país; y otros momentáneos, inmediatos, que no consistían más que en ofrecer el perdón a los sublevados, prometiéndoles un trato dulce y magnánimo, siempre y cuando entregaran a los promotores e incitadores de la violencia que estaban atrás de ellos. Al gobierno le correspondería, en todo caso, establecer los arbitrios pertinentes para lograr el éxito y contener el mal. ${ }^{3}$

Obviamente la postura de El Monitor Republicano iba a tono con su creencia de que, como seres de segunda, los mayas eran incapaces de promover por sí solos el levantamiento, encontrándose tras ellos diversos grupos, principalmente el de los anarquistas. Le quedaba claro al diario que no se trataba de una guerra social, aunque reconocía que a aquéllos se les tenía en el abandono, sino de una cuestión política en la que éstos, valga la contradicción, pretendían utilizar a los indígenas para establecer en el gobierno a una persona con poderes omnímodos, la cual no reconocería límites ni valladar alguno, ni aun el de la propiedad. Y éste era el peligro mayor, pues, repartida la tierra, al mismo tiempo de que los mayas triunfaran vendría la debacle, profetizó, ya que, incapaces como eran de gobernarse, no tardarían en volver a su estado anterior al de la llegada de los españoles, el cual se caracterizaba por la división en reinos, imperios y señoríos en guerra permanente. Con una situación así, y ante el peligro de una conflagración

\footnotetext{
${ }^{2}$ Hemeroteca Nacional (HN), El Monitor Republicano, año 5, México, miércoles 6 de junio de 1849 . número 1485 , pp. 2-3.

${ }^{3} \mathrm{Idem}$.
} 
general, las potencias extrañas no verían impasibles las escenas de sangre y destrucción, y caerían sobre México, cuyos incultos habitantes no podrían defender, acabándose la patria para siempre. ${ }^{4}$

El enemigo, en suma, no era la raza indígena, sino los anarquistas, a los que sí se podía aplicar todo el peso de la ley, por perversos, por antipatriotas. Mas la raza indígena, aunque no enemiga, sí era un lastre para el país, por ignorante, por pobre, por bruta; de ahí la necesidad de su desaparición, pero no de manera violenta.

Según El Universal, las propuestas de El Monitor Republicano no eran más que quimeras, poco útiles a los principios de la conveniencia, por más que estuvieran plagadas de humanidad y filantropía. Su conclusión era tajante: como los indígenas eran bárbaros que estaban enfrascados en una lucha contra la civilización, y como ésta poco podía hacer en favor de unos entes cuyo carácter e instintos no les habían permitido salir del rango de cosas, no había otra alternativa que avasallarlos, o aceptar la idea de ser exterminados por ellos. ¿Ciudadanos los indios? Nunca. ${ }^{5}$

Casi un lustro antes, Carlos María de Bustamante había llegado a una conclusión semejante, aunque menos radical, en torno al papel social de estos últimos, argumentando que si bien los indios eran hijos de México, no se les podía considerar como parte del pueblo mexicano, ya que carecían de las dotes necesarias a ello debido a su falta de educación y a su ferocidad contra las otras razas. Para él, el pueblo estaba integrado por hombres que querían ser gobernados por principios fijos, por hombres que conocían su dignidad y sus derechos, por hombres que cumplían con el deber de no ser omisos ni tolerantes con la explotación, y que apelaban a la insurrección para recobrar su libertad perdida. ¿Cumplían con estos requisitos los indígenas? No, pues a ellos sólo los movía el odio que sentían contra todos los demás, alentados en parte por lo excesivo de los tributos y las exacciones que se les habían impuesto desde la Colonia. ${ }^{6}$ No aceptaba, sin embargo, su eliminación sino su integración, utilizando al efecto el proceso del cual carecían: el educativo.

Este mismo autor propuso en ese entonces, 1844-1845, que los encargados de implementar labor tan apremiante debían ser los misioneros, especialmente los jesuitas, por contar con la experiencia mínima requerida para ello. ${ }^{7}$

Después, nueve años más tarde, el a veces exaltado periódico santanista y en ocasiones oportuno liberal, El Ómnibus, pediría de igual manera que se recurriera a las misiones para evitar las irrupciones de los bárbaros, a la par que se implementaban otras medidas como la colonización y la inmigración europea. ${ }^{8}$

\footnotetext{
${ }^{4}$ Ibidem, sábado 23 de junio de 1849 , número 1502, pp. 3-4.

${ }^{5}$ Para más detalles sobre esta disputa ideológica, pueden verse ambos periódicos en sus editoriales de marzo a septiembre de 1849 .

${ }^{6}$ Carlos María de Bustamante, Apuntes para la historia del gobierno del general D. Antonio López de Santa-Anna, desde principios de octubre de 1841 hasta 6 de diciembre de 1844, en que fue depuesto del mando por uniforme voluntad de la nación, México, Imprenta de J. M. Lara, 1845, pp. 332-337.

${ }^{7}$ lbidem, pp. 153-154.

${ }^{8} \mathrm{HN}$, El Ómnibus, tomo II, México, jueves 21 de julio de 1853, número 106, p. 1, y lunes 25 de julio de 1853 , número 109 , p. 1.
} 
Con el triunfo de los liberales, a finales de la década de 1860 y principios de la de 1870 la postura de la aniquilación mediante la fuerza extrema se fue matizando, salvo si se trataba de "grupos rebeldes de saña desenfrenada", por supuesto, sustituyendo aquel concepto por otros que dejaban de lado la cuestión de la presencia física, pero no la cultural ni la racial. Así, palabras como modificación y transformación, aunque más suaves y redentoras, escondían en el fondo un anhelo semejante al de aquélla: que los indígenas desaparecieran como tales, pues sólo de esa manera dejarían de ser una carga para la nación. Claro es que el dilema, como siempre, no era para los indígenas, sino para los otros, para los mexicanos de cepa, como dirían algunos. A esa conclusión había llegado también, por ejemplo, Francisco Pimentel en 1864:

El resultado de nuestras observaciones nos conduce naturalmente a esta tremenda disyuntiva como único y definitivo remedio imatar o morir!... afortunadamente hay un medio con el cual no se destruye una raza sino que sólo se modifica, y ese medio es la transformación. ${ }^{9}$

Pero, ¿transformación en qué, y hacia dónde? La solución fue coincidente: en todos sentidos, en lo material y lo ideológico, para que se vincularan ya no con la propiedad comunal, sino con la privada, y para que dejaran la pereza y se volvieran productivos, susceptibles de todos los beneficios del trabajo, en especial los que ofrecía la nueva panacea que — se suponía- llevaría al país a la modernidad: la industrialización.

Por lógica, para esto también había niveles. No se trataba de emparejarlos con los sectores dirigentes, los criollos y las clases medias, las de los intereses públicos, sino con la clase proletaria, la que, como afirmaban desde mediados de siglo, aunque satisfacía con su trabajo sus necesidades más precisas, seguía dependiendo de los partidos para participar en la vida nacional. ${ }^{10}$

Finalmente, las opciones más viables para llevar a buen término tales planteamientos no eran sino tres: la educación, la "suave disciplina", y la colonización, destacando sobre todo la primera, la que se volvió — como nunca antes_, tema frecuente durante la primera presidencia de Porfirio Díaz (1877-1880), no sólo por la promoción de éste en pro de la paz como factor de progreso, sino también ante la amenaza que implicaba la presencia del comunismo en el país.

\section{b) La fuerza del derecho versus el derecho de la fuerza}

Considerandos más, considerandos menos sobre la guerra de los mayas, hay una diferencia fundamental entre la prensa de la ciudad de México de mediados del

\footnotetext{
${ }^{9}$ Citado por Luis Villoro, Los grandes momentos del indigenismo en México, México, Ediciones de la Casa Chata, 1979, p. 184.

${ }^{10} \mathrm{HN}$, El Monitor Republicano, op. cit., sábado 23 de junio de 1849 , número 1502, pp. 3-4.
} 
siglo XIx, y la de la primera administración porfirista. Si en aquélla se debatía sobre la conveniencia o no de que la inferioridad y la barbarie de los indios fuera motivo de redención, o bien de esclavitud y exterminio, en ésta ya no había dudas: redención, sí, mediante la educación y el trabajo. ¿El uso de la fuerza militar? Únicamente en casos extremos, pero sin exterminio, con regeneración obligada vía la educación y el trabajo. Además, de igual manera en el último caso se procuró explicar el porqué de la guerra, llevándolo más allá de la simplista tesis del odio racial.

Lejos quedaron, también, las propuestas de solución basadas en una nueva conquista espiritual mediante la revitalización de las misiones, como propuso $E I$ Ómnibus en $1853 ;^{11}$ o la división de Yucatán en dos territorios, uno de blancos y otro de indios insurrectos, medida en la que tuvo gran interés Inglaterra, al grado de que se comprometió a negociar con los rebeldes el abandono de las armas y su inserción al trabajo. Obviamente, como dijo en esos momentos Le Trait d' Union, los británicos se entrometieron no por cuestiones de humanidad, sino por los negocios que sostenían con los mayas y su anhelo de apoderarse de dichas tierras en conflicto. ${ }^{12}$

Apenas unos días después de la toma de posesión presidencial de Porfirio Díaz, haciéndose eco de su llamado a la paz y la estabilidad política, pero también con el ánimo de mostrarle a éste parte de los problemas prioritarios del país, Xiutecuhtli asentó en la parte editorial de El Monitor Constitucional que ya era tiempo de que México volviera los ojos hacia la raza indígena, antes de que ésta, con la fuerza y con justicia, reivindicara el puesto que le correspondía en la vida nacional. Añadió que, "víctima de la sórdida avaricia de los propietarios, de la brutalidad de los gobiernos y de la implacable codicia de los clérigos", la población indígena estaba, en efecto, sumida en la miseria, sin cultura y explotada en todos sentidos, pero que esto mismo podía provocar de manera natural su reacción, haciendo pagar cara su soberbia a la raza mixta, sobre todo porque esta última era seis o siete veces menos que aquélla en cuanto al número de habitantes. Por ende, era hora de que el gobierno dejara atrás las intrigas personales, las pequeñeces y las puerilidades ridículas, y se abocara a solucionar las necesidades y las aspiraciones de los indios. ${ }^{13}$

No dijo de qué manera se podía lograr esto, pero dicho periódico publicó meses después más reflexiones sobre el tema, señalando en una de ellas que, ante el inminente avance del fanatismo y el peligro de que los horrores que asolaban a la península de Yucatán se extendieran a todo el país, no había más que tomar acciones adecuadas inmediatas, siendo la primera el establecimiento de escuelas. Sólo en éstas, aseguró el firmante Carranco, se labraría "el porvenir de esa

\footnotetext{
${ }^{11}$ HN, El Ómnibus, op. cit., jueves 21 de julio de 1853, número 106, p. 1.

${ }^{12}$ Citado por El Monitor Republicano, op. cit., domingo 12 de agosto de 1849, número 1552, p. 4.

${ }^{13} \mathrm{HN}$, El Monitor Constitucional, II época, México, sábado 19 de mayo de 1877 , número 28 , p. 1.
} 
juventud indígena entre la que hay talentos privilegiados tan notables como el de Benito Juárez y otros."14

Para principios de 1878 , desde las páginas de El Monitor Republicano, Juvenal" abordó el asunto en esa misma perspectiva, pidiéndole tanto al gobierno general como a los gobiernos locales, que aseguraran el sendero que llevaba hacia la civilización, antes de que el país se viera en una situación mucho más grave: la del comunismo, misma que se empezaba a gestar en diversas partes de Hidalgo, donde los pueblos reclamaban por la fuerza tierras que estaban en manos de hacendados. Este uso de las armas, en lugar de las leyes, no era otra cosa que una vuelta a la barbarie, al salvajismo, agregó..$^{15}$

$\mathrm{Al}$ respecto, dio a entender que si bien existían problemas con los grupos indios en varias partes de la República, éstos no eran demasiado graves como para no solucionarlos en lo inmediato ya sea mediante la ilustración, el consejo y la aplicación de la justicia, o incluso la represión. Dicha tarea era más que imprescindible, antes que aquellas comunidades, indómitas y vengativas de por sí, se vieran afectadas de esa doctrina extranjera que, dada su tendencia a acabar con la propiedad, podría provocar una verdadera borrasca en todo el territorio nacional. ${ }^{16}$

De entrada, concluyó, se debía vigilar estrechamente a diversas gentes de razón, que promovían el descontento sólo para seguir figurando entre los indígenas como monarcas absolutos.

Aunque del mismo periódico y con la misma concepción, el boletinista J. P. de los Ríos asumió una postura diferente en torno a la propuesta de Juvenal sobre la represión hacia los indígenas, ya que, dijo, éstos no eran sino meros instrumentos de gente ajena a ellos, a la que sí se debía castigar con todo el rigor de la ley. Ésta fue su opinión:

La civilización ha traído, entre otras ventajas, la de sustituir la fuerza del derecho al derecho de la fuerza. Esto es lo que distingue precisamente a las sociedades civilizadas de las tribus bárbaras. Así, mientras mayor es el progreso de un pueblo, más restringido se halla el abuso de la fuerza bruta.

Nosotros hemos hecho importantes conquistas en todas líneas; pero desgraciadamente, tenemos que luchar aún con un obstáculo que apenas parece superable. Nos referimos a la ignorancia de una gran parte de nuestro pueblo, y especialmente a la raza indígena. La necesidad de instruirle es más urgente de lo que parece, pues mientras esto no se haga, estamos expuestos a que mal dirigidos por muchos de los que conservan entre ellos el prestigio del antiguo cacicazgo, lejos de ser un elemento de vida y progreso, lo sean de disolución para nuestra sociedad, de la

${ }^{14}$ lbidem, miércoles 5 de septiembre de 1877 , número 118 , p. 1.

"Nota del editor: de acuerdo con el Diccionario de seudónimos, anagramas, iniciales y otros alias, de María del Carmen Ruiz Castañeda y Sergio Márquez Acevedo, Juvenal es Enrique Chávarri, periodista y director de El Monitor Republicano.

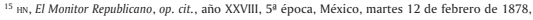
número 37 , p. 1.

16 Para más detalles, véase sobre todo sus editoriales de enero a marzo de dicho año, en especial el titulado "La nubecilla blanca", que se publicó el viernes 25 de enero, número 22 , p. 1. 
que están casi separados por la ignorancia del idioma. La raza indígena, inteligente, dócil, afectuosa, útil, cuando está bajo el influjo de la educación, es ruda, indomable, rencorosa y peligrosa cuando tiene quien la mal aconseje en su estado de abandono. Entonces la astucia y la obstinación, que son sus caracteres distintivos, sirven a los indígenas para arrojarse a los mayores atentados, burlando la acción civilizadora de la ley y dando rienda suelta a sus instintos y a sus odios.

Esto ha sucedido y sucederá mientras el gobierno no cuide, por una parte, de extender hasta los más pequeños poblados la acción civilizadora de la educación y la instrucción, y por otra, mientras no se decida a reprimir en los instigadores de los pueblos ignorantes los atentados, que por su causa cometen los mismos indígenas, quienes sólo son el instrumento de esos mismos instigadores que, aprovechando el aislamiento relativo a que reduce la falta de idioma a los indigenas, les hacen concebir una idea errónea de los derechos y los deberes que tienen en sociedad.

Dígalo si no lo que está pasando actualmente en la República. ${ }^{17}$

Es claro que en ambos casos, el de Juvenal y el de de los Ríos, el problema señalado tenía una sola vertiente, un solo punto de vista, el cual no era el que pudiera manifestar la raza indígena sobre sí misma. Por lo tanto, cuando hablaban de derechos y deberes erróneos, lo hacían en el entendido de que ésta se oponía a vivir bajo el apego a las leyes, razón por la cual no respetaba ni la propiedad ni la paz, y se negaba a integrarse a un esquema de trabajo productivo, ya en la hacienda o en la fábrica, que fuera más allá de la simple subsistencia.

Obviamente, si no les concedían a los indios el mínimo requisito de la palabra, mucho menos les podían otorgar el beneficio de la duda, en lo que corresponde a su capacidad para organizar un movimiento de resistencia y lucha socialista, asumiendo que no eran sino entes ignorantes, sometidos a la influencia de intereses mezquinos promovidos por malos mexicanos, por personas que sólo obedecían a un puro espíritu de imitación, en palabras de José María Vigil.

En ese sentido, los socialistas de entonces reconocieron en agosto de 1878 que sí, que en efecto ellos estaban detrás de varios de los movimientos de oposición, pero no por seguir un modelo extranjero, sino por la necesidad que había de una reforma social verdadera que obligara a los indígenas a participar de manera frecuente en el progreso. Así, su valoración sobre estos últimos no era en lo absoluto diferente a la que tenían los liberales y los conservadores, de acuerdo al testimonio del semanario La Internacional:

Cumple pues a nuestro deber, despertar a éste de su letargo y hacerle comprender todos sus derechos y de esa manera, sacerdotes de la civilización, lograremos hacer de un pueblo de estúpidos esclavos, un pueblo de hombres libres. ${ }^{18}$

Según Félix Riquelme y demás colaboradores de dicha publicación, la labor que estaban llevando a cabo tenía implícita la recuperación de tierras mal habi-

${ }^{17}$ HN, El Monitor Republicano, op. cit., año XXVIII, miércoles 3 de abril de 1878, número 80, p. 1.

${ }^{18}$ HN, La Internacional, tomo I, México, domingo 11 de agosto de 1878, número 6, p. 4. 
das, pero no con el objetivo de acabar con la propiedad privada, sino con el de lograr una nivelación gradual y equilibrada de la misma, requisito fundamental para el pleno goce de los derechos que la naturaleza había concedido a los seres humanos: la libertad, la igualdad y la fraternidad. Por ende, recomendaban a los hacendados que devolvieran lo que no les pertenecía por justicia de Dios, representada en la justicia del pueblo, antes de que toda la raza indígena se levantara de su letargo y reclamara sus derechos ultrajados y su individualidad perdida. ${ }^{19}$

Como en ocasiones anteriores, Juvenal fue quien más trató el asunto mediante sus editoriales en las páginas de El Monitor Republicano. Ahí, hizo reiterados llamados para que el gobierno resolviera por fin toda esta problemática, apelando especialmente al estricto apego al derecho. En este caso, su optimismo era total, pues creía que más resolvían la propaganda de doctrinas de paz y el justo actuar de los jueces, que la vía de las armas. Basaba este supuesto en un hecho concreto: salvo en el caso de los mayas, la violencia de esos momentos en Hidalgo, Michoacán, Puebla, Veracruz, Estado de México, y otros sitios, se debía a reclamos de tierras, y no a un choque de razas, no a una guerra de castas. Por lo mismo, si se lograba que los afectados recurrieran a los tribunales para resolver sus quejas, y si en éstos se obligaba a los magistrados a actuar con justicia, so pena de ser acusados ante la prensa y ser sometidos a la verguienza pública, entonces todo volvería a la tranquilidad. Así, el riesgo estaba en el hecho de que no se lograran acuerdos, y que se vincularan las protestas indigenas de todo el país, lo que llevaría irremisiblemente al desastre social. Dicha unión era la que pretendían los comunistas. Afirmó al respecto en marzo de 1879:

Ya en otra vez hemos hecho notar, cómo entre esas masas de sencillos habitantes de los campos se deslizan algunos que les hacen comprender muy mal sus derechos y los inducen a demasías que ocasionan, que han ocasionado ya más de un conflicto. Esta conducta es poco patriótica; no son éstos los momentos de estar predicando una guerra la más desastrosa; en ningún momento sería esto aceptable ni por un instante, pero en las circunstancias actuales es doblemente peligroso.

¿Qué sería de este pueblo infeliz, si al estallar las revoluciones que ya se preparan viniese una guerra social a darle el golpe de gracia, si en medio del desorden, si entre las ambiciones que de un modo tan tremendo nos están amenazando, se escucharan las fatídicas doctrinas del insensato comunismo? ${ }^{20}$

Una opinión diferente sobre este clima de tensión tenía el periódico lerdista El Republicano, crítico acerbo de todo lo que hiciera Porfirio Díaz. No obstante, coincidía plenamente en el caso de la situación maya. Desde sus primeros números en enero de dicho año, argumentó que si bien muchos de los pueblos de los estados señalados estaban en lo justo al sublevarse contra el gobierno opresor e ilegítimo, ya que no hacían sino defender sus tierras de la avidez de los fuertes,

${ }^{19} \mathrm{lbidem}, \mathrm{pp} .1-2$. Véase sobre todo el texto editorial, que lleva por título: "Indigenas y hacendados".

${ }^{20} \mathrm{HN}$, El Monitor Republicano, op. cit., año XXIX, $5^{\text {a }}$ época, México, viernes 21 de marzo de 1879. número 69 , p. 1 . 
no era ni podía ser el caso de los mayas yucatecos, verdaderos depredadores, a los que sí había que poner fin de cualquier manera. ${ }^{21}$ De no hacerlo así, el presidente usurpador tendría una mancha más en su odiosa dictadura.

A fines de marzo, las noticias de una posible alianza entre los mayas del oriente y los del sur de la península, con la amenaza de incursiones inmediatas sobre el resto del territorio yucateco, puso a todos en alerta. La Patria señaló que el peligro era tan real, que el gobierno necesitaba mandar por lo menos ocho mil fusiles - y hombres, supongo - , para acabar de una vez por todas con la guerra; de lo contrario, era seguro que para 1880 los rebeldes serían dueños de todo el país, es decir, de todo el estado. 22

Los lerdistas no desaprovecharon esta oportunidad para volver a criticar al gobierno y a los porfiristas en general, por supuesto, vía uno de sus editoriales del 24 de abril de ese mismo año titulado: "La guerra de castas". Este documento hemerográfico es uno de los más significativos del periodo que aquí se trata, pues, aunque abunda en calificativos adversos al régimen y a los propios mayas, a los que juzga de salvajes e ignorantes, es de los pocos que resalta la necesidad de explicar "el origen del mal" mediante el conocimiento histórico, ya que sólo de esa forma -aseguró-, se podría comprender toda la complejidad y lo difícil de la situación que se vivía.

Empieza con la conquista. Reconoce que en la península tuvieron que pasar más de veinticuatro años de sangrientas batallas, hambrunas y pestes, para que los conquistadores españoles pudieran implantar su dominio, y eso con la ayuda del rey de Maní, Tutul Xiu. No obstante, añade que dicha conquista no se pareció en nada a la de la Nueva España, ya que mientras en ésta se destruyó todo y se implantó una civilización que permitiría la cruza de razas y la preponderancia del elemento europeo, en Yucatán no fue así:

...el país contenía una población indígena numerosa y aguerrida, grandes y populosas ciudades; sus habitantes eran de un carácter belicoso, duro e intransigente; la corriente de inmigración era insignificante, pues fuera de Campeche, Mérida, Valladolid y Bacalar no había una sola población española; y por último se dio a Yucatán un gobierno propio, que a la par que su posición geográfica, lo aislaba de la Nueva España.

De aquí resultó que el elemento indígena predominara en ese país, en la proporción de diez a uno.

$\mathrm{Y}$ ese predominio fue tal, que en Yucatán tuvo lugar un fenómeno que sólo reconoce igual en la historia de Roma. Los hunos, los godos; todos los conquistadores del imperio, tuvieron que aprender las leyes, las costumbres y el idioma de éste. Los conquistadores de Yucatán y sus descendientes han tenido que aprender la lengua de los vencidos.

¿Qué podía resultar de ese estado social?

Lo que era preciso: que la raza indigena, valiente e inquieta, aprovechase todas las oportunidades que se le viniesen a las manos para sacudir el yugo. ${ }^{23}$

${ }^{21}$ HN, El Republicano, año 1, México, martes 21 de enero de 1879, número 17, pp. 1-2.

${ }^{22}$ HN, La Patria, año III, México, martes 1 de abril de 1879, número 593, p. 2.

${ }^{23} \mathrm{HN}$, El Republicano, op. cit., jueves 24 de abril de 1879, número 91, p. 2. 
Luego, tras señalar que las rebeliones mayas más notables fueron la de Sacalum en 1635, la de Bacalar en 1636, y la de Kisteil en 1761, esta última comandada por Jacinto Canek, añade que con la Independencia no sólo no cambió en nada el orden social de la región, sino que se incrementó la sujeción de los indios, ya que se les obligó a participar como carne de cañón en las innumerables guerras civiles de la época.

Así, el indio fue arrancado de su hogar, y llevado al matadero muchas veces.

Dos graves inconvenientes resultaron de aquí: primero, exasperar al indio, añadiendo combustibles a sus odios: segundo, hacerle conocer su fuerza y lo que valía. ${ }^{24}$

Sobre esta base, los nuevos síntomas de sublevación iniciaron en 1834, con motivo de unas elecciones en Valladolid, hasta desembocar, en enero de 1847 , otra vez en Valladolid, con el saqueo de dicha villa y la muerte de muchos de los pobladores blancos, sin distinción de sexos, ni edades. Todo esto, mientras Miguel Barbachano y Santiago Méndez se disputaban el poder, siendo gobernador el primero. Desde ese momento se desató una guerra salvaje, sin cuartel, devastadora, como la hacían los hunos, que no acabó con Yucatán en los primeros años de lucha gracias a esfuerzos heroicos, implementados a costa de mares de sangre y de todos sus tesoros, como que se había levantado un ejército de veinticinco mil hombres. Aunque para la década de 1860 ya se había conseguido una paz relativa con los sublevados del sur, en la parte oriente de la península no ocurrió lo mismo, lanzándose desde aquí incursiones continuas contra los pueblos civilizados.

Tal era la historia y el origen de la guerra de los mayas yucatecos, afirmó el periódico, misma que no dejaba lugar a dudas sobre las consecuencias que podía traer a México la nueva alianza que se gestaba entre los bárbaros del sur y los del oriente, sobre todo porque su éxito no tardaría en involucrar a sus hermanos de Campeche y Tabasco, dada la inestabilidad política existente en todas partes. Por si fuera poco, de Tabasco la rebelión se podía extender a los chamulas y a otros pueblos de Chiapas, donde estaba mal apagado el fuego de la sublevación de 1869; y de éste a Oaxaca, con los mixes por delante, pues su odio a los blancos era tal, que no permitían su presencia entre ellos, ni aun como transeúntes. Si tal panorama se hacía realidad, se pregunta, “¿qué sería de nuestros pueblos con esa avalancha de 300,000 salvajes?" De ahí la importancia que tenía el contener semejante posibilidad, adujo.

Mas esto no se podía hacer mandando al efecto sólo quinientos hombres y cien fusiles, mientras holgazaneaban dentro de las ciudades cerca de cuarenta mil efectivos, perdiendo el tiempo y desmoralizándose. "Pero desesperemos: tratándose de las grandes cuestiones sociales, Tuxtepec hace oídos de mercader" - concluyó. ${ }^{25}$

$$
\begin{aligned}
& { }^{24} \text { Idem. } \\
& { }^{25} \text { Idem. }
\end{aligned}
$$


Al parecer toda esta tensión de la prensa no era compartida por el presidente Díaz ni en lo público, ni en lo privado, a juzgar por las pocas referencias que ofrece en su archivo personal sobre dicho conflicto. $Y$ en ese sentido no se le podía acusar de desconocimiento, ya que estaba muy bien enterado. Por ejemplo, desde un año antes el coronel Daniel Traconis, encargado de la pacificación de la zona, le había informado que el estado estaba más que tranquilo, debido a que faltaba muy poco para acabar con los rebeldes mayas. Ante tal situación, le pidió que tendiera su mano protectora sobre la península, y lo apoyara con la implementación de una campaña militar en forma, para la que le eran suficientes dos mil hombres del ejército federal, dos mil hombres de la guardia nacional del estado, dos mil cargadores y macheteros que harían también el servicio de zapadores, una batería de obuses de montaña, una sección médica con elementos de hospital, y doscientas mulas de carga. Pero Díaz no hizo mayor caso, recomendando el asunto a Carlos Peón. ${ }^{26}$

No fue sino hasta agosto de 1879 cuando el presidente hizo pública su anuencia para enviar refuerzos a Yucatán; noticia que celebraron de inmediato sus adeptos con bombo y platillos - como se dice-, no sin antes hacer hincapié en que tal determinación era parte de un acuerdo entre Díaz y diversos particulares, para culminar de una vez por todas con la intranquilidad de tan rica región. $L a$ Libertad fue de los primeros en festejar, teniendo buen cuidado siempre en dar a entender que no importaba el número de elementos, armas y tiros que se destinasen, ya que aunque fuera con pocos se podrían defender muy bien las plazas, si se implementaban fuertes y reductos apropiados. ${ }^{27}$ En ese sentido, al parecer basaba su confianza en el supuesto de que, según informes, los insurrectos no iban más allá de los cinco mil hombres, todos animados con la profecía del Chilam Balam, que decía había llegado el tiempo de que los blancos desaparecieran de dicha tierra. ${ }^{28}$

De acuerdo con esta publicación y con La Tribuna, entre los particulares interesados en el proceso de pacificación figuraban prominentes hijos de la península, como Justo Sierra, Eleuterio Ávila, Ricardo Cicero, y Santiago Blanco, la mayoría de ellos muy ligados al régimen. De hecho, éstos fueron los principales promotores de la Sociedad Colaboradora en México de la Sociedad Patriótica Yucateca, con el propósito de estudiar y poner en práctica los medios más eficaces para culminar con la guerra de castas.

La Sociedad Patriótica Yucateca se fundó en 1874 en Mérida con la misión, según su secretario J. Antonio Alayón, de sostener y defender la causa de la civili-

\footnotetext{
${ }^{26}$ Universidad Iberoamericana (UIA), Colección Porfirio Díaz (CPD), legajo III, doc. 23. "Apuntes relativos a la guerra de castas en Yucatán, escritos por el coronel don Daniel Traconis". Mérida, junio de 1878 .

${ }^{27}$ Para este periódico la guerra de los mayas no representaba ningún peligro real para el país, y en ese tenor fueron la mayoría de sus notas desde mayo de 1879 hasta septiembre del mismo año. Reconocía, eso sí, que era necesario mantener la vigilancia para evitar cualquier sorpresa.

${ }^{28}$ HN, La Libertad, año II, México, domingo 18 de mayo de 1879 , número 115, p. 3.
} 
zación contra la barbarie, así como "de hacer pedazos para siempre las horribles y enmohecidas cadenas de los esclavos de Chan Santa Cruz". Sobre esta base, sus miembros estaban comprometidos con tres objetivos fundamentales:

10. Pedir constantemente a todos los gobiernos que en adelante se establecieren la conclusión de la guerra que aniquila al país. $2^{\circ}$. Procurarse recursos para auxiliar a los inutilizados, huérfanos y viudas de la guerra de indios y para arrancar de las garras de los salvajes a más de doscientos prisioneros que existen en su poder, y $3^{\circ}$. Cuidar de los hijos de los que han fallecido y fallecieren en dicha campaña, procurando que asistan a las escuelas de artes y oficios, y acudir a las autoridades competentes para encaminar a los que desgraciadamente se desviaren, a efecto de ser útiles a sí mismos y a su patria. ${ }^{29}$

Aprovechando la cercanía de aquéllos con el presidente Díaz, ante los rumores de un recrudecimiento del conflicto Alayón les pidió intervinieran para que por fin se pusiera término eficaz a la guerra, amén de que lo apoyaran también con diversos recursos económicos. Así, el 4 de septiembre de 1879 se reunieron las personas referidas para conformar la Sociedad Colaboradora, quedando como presidente Santiago Blanco, como vocales Eleuterio Ávila y Ricardo Cicero, y como secretario Justo Sierra. ${ }^{30}$

En opinión de Homo, articulista de La Tribuna, la organización de ambas sociedades, la yucateca y la mexicana, era tal, que muy pronto les cabría la gloria de haber dado cima al grandioso proyecto de la paz, la cual se tenía que lograr más por el camino del convencimiento que por el de la efusión de sangre. ${ }^{31}$

Sin embargo, la paz no era suficiente, añadió poco después la redacción de dicho órgano, ya que ella sola no garantizaba el que se resolviera el problema real, el meollo del asunto: ¿Qué hacer con los indígenas? ¿Cómo insertarlos en la modernidad liberal? ¿Cómo hacerlos partícipes del progreso?

La respuesta del periódico fue tajante: haciéndolos productivos, haciéndolos mano de obra disponible y competitiva vía la educación. En suma, hacer que dejaran de ser indios. Dijo al respecto en su editorial del 29 de julio de 1880:

La raza indígena no carece de inteligencia: está enervada, postrada y es difícil que por sí misma salga de semejante abatimiento: preciso es, pues, ayudarla con provecho de todos, preciso es despertar su inteligencia y convertirla de la pasividad y de la indiferencia, a la vida activa e intelectual. Esto no es sólo un deber moral; es un deber social; la familia india, en el estado en que se halla, no produce ni la tercera parte de lo que debiera producir, ni concurre a la civilización en que vivimos; es un miembro enfermo de la sociedad, que es indispensable curar por la instrucción

${ }^{29}$ lbidem, miércoles 24 de septiembre de 1879 , número 222, pp. 2-3.

$30 \mathrm{lbidem}$, viernes 5 de septiembre de 1879, número 207, p. 3. Para el Reglamento, con los derechos y las obligaciones de los socios, véase hn, La Tribuna, tomo 1, México, sábado 27 de septiembre de 1879 , número 18 , pp. 1-2.

${ }^{31}$ HN, La Tribuna, op. cit., sábado 27 de septiembre de 1879, número 18, pp. 1-2. 
progresiva y haciéndole intervenir directamente en el movimiento humano. Los medios que convendría emplear desde luego redúcense, en nuestro concepto, a poner a los indios en circunstancias a propósito para que aprendan y se eduquen; se nos dirá que las escuelas y los centros literarios están abiertos para todos sin ninguna clase de exclusión, pero esta accesión oficial está contrariada por preocupaciones y costumbres que importa extirpar, la acción individual tiene en estas empresas mucho más influjo que la acción oficial; una asociación constituida para proteger la instrucción de los indios daría fecundos resultados, apoyada por la representación oficial, y el conocimiento de nuestros propios intereses sería el mejor aliciente para que se procurase multiplicar las fuerzas vivas del país. ${ }^{32}$

Con razonamientos semejantes, era lógico que al indígena no se le concediera el derecho a la más mínima opinión. Como siempre, debía dejar que otros decidieran por él, que le marcaran lo más conveniente para su vida. Y aquí los mestizos y los criollos se arrogaban el mejor punto de vista, dígalo si no F. J. Enciso, porfirista y gonzalista convencido y confeso, quien en su artículo "Un cáncer social", publicado en La Tribuna el 4 de diciembre de 1880, dio a entender que el mejor indígena era el indígena ya muerto, el del pasado, del cual hasta se podía sentir y mostrar motivo de orgullo, porque ése sí había contribuido a enaltecer nuestra historia con grandes y magníficas obras. ${ }^{33}$

No es de extrañar que Enciso manifestara semejante idea, si el ilustre y culto maestro José María Vigil le mostraba a él y a otros el camino a seguir en ese asunto desde tiempo atrás, al afirmar que si México - cuerpo enfermo y sin derechos fundamentales-, no quería estar por debajo de la escala humana debido a la opresión e ignorancia en que vivía toda su población indígena, no tenía otra opción más que obligar a ésta a transformarse, abandonando su lengua y sus costumbres por ser reacias a la penetración del conocimiento científico y literario. Claro que había que fijar la vista en ellos, agregó Vigil, pero sólo con un interés arqueológico, toda vez que debía considerárseles como condenados a desaparecer, hecho lamentable tal vez, pero necesario pues únicamente así se podría lograr el progreso. ${ }^{34} \mathrm{El}$ punto fundamental debía ser, entonces, minar los llamados idiomas autóctonos. Según él, Guillermo Prieto cometía un error lamentable cuando apostaba por la preeminencia de éstos para llevar al indio por el camino de la reconciliación de los espíritus, pues ninguno de ellos, pese al grado de perfección que tuviera, era capaz de ser un instrumento adecuado para transmitir la suma del saber que constituía el caudal de la civilización moderna. Por lo mismo, si se quería el desarrollo del país, pese a los lamentos de los anticuarios la desaparición de las lenguas nativas se hacía forzosa, más

\footnotetext{
32 Ibidem, jueves 29 de julio de 1880 , número 256 , p. 1.

${ }^{33}$ HN, La Tribuna, op. cit., sábado 4 de diciembre de 1880, número 362, p. 2.

${ }^{34} \mathrm{HN}$, El Monitor Republicano, op. cit., martes 1 de julio de 1879 , número 156, p. 1, y miércoles 26 de noviembre de 1879 , número 283 , p. 1.
} 
cuando era bien sabido lo mucho que tenía de aventajado un pueblo en el que existía la unidad del lenguaje. ${ }^{35}$

Volviendo a Enciso, en el artículo señalado refiere que el pasado yucateco había sido glorioso, pues los mayas tuvieron el valor y la energía necesaria para no dejarse subyugar en forma completa por los españoles, pese a la traición de pusilánimes como Tutul Xiu y la superioridad de las armas de fuego de la llamada civilización europea. Ese valor y esa energía se mostraron de igual manera en las múltiples rebeliones contra los españoles, durante los cerca de tres siglos de dominación, destacando especialmente la de Jacinto Canek, vigorosa, seria, y enaltecedora. Además, ese valor y esa energía explicaban en mucho el hecho de que el idioma de los conquistadores fuera una planta exótica en el célebre país de los antiguos mayas; esto último a tal grado, que los hijos de España se hallaban respecto a los indígenas en el mismo caso que los francos respecto de los galos.

Y ahí acabó la lisonja, porque sus consideraciones sobre los mayas posteriores a la Independencia fueron acerbos. No lo dice directamente, pero sí da a entender que ese vigor que utilizaron contra los invasores ya no era válido, ya no venía al caso cuando se trataba de los hijos de una misma patria, y con un mismo interés, supuestamente: el de poner a México entre los primeros planos de las naciones civilizadas del mundo. Esto parecía lógico, pero los mayas no lo entendieron así y siguieron con sus mismos hábitos, su carácter, su modo de ser, su apego a la tierra, su necedad en conformarse con lo poco que ésta les daba, por flojos e indolentes. Y sucedió lo que tenía que suceder, afirmó: la irrupción de los salvajes, "peores mil veces que los comanches", y que no habían provocado otra cosa más que la ruina de esa hermosa comarca.

La independencia en nada cambió los hábitos, el carácter, el modo de ser de los indios yucatecos.

Tascaron éstos el freno, por decirlo así, de la dominación de los blancos; pero esperaban el primer momento para terminar con la raza conquistadora.

Tomaban parte en las luchas civiles, no por convicción, sino por procurar la destrucción entre sí, de sus enemigos.

Hubo una época en que inconsideradamente los partidos políticos tomaron a su servicio a esos indígenas del todo bárbaros, sin recordar la historia del Bajo Imperio.

Y sucedió lo que suceder debía.

En 1847 luchaban los partidos personalistas de los señores Barbachano y Méndez.

Uno de ellos apela al elemento indígena, y al toque de rebato de los salvajes, responde el saqueo de Valladolid.

Como si esto hubiera sido el mot d' ordre de los enemigos de la civilización, una irrupción de bárbaros invade la península, llegando hasta las puertas de Mérida.

Ya no hay partidos políticos, es la guerra de la civilización contra la barbarie.

35 Ibidem, miércoles 26 de noviembre de 1879 , número 283 , p. 1. 
Por donde quiera se ven pueblos en ruina, y además de trescientas haciendas y cien ranchos, desaparecen del mapa de Yucatán, Becanchén, Kancabchén, Sacalaca, Petulillo, Dzemul, Saban, Uaymax, Chunhulub, Polyné, Tituc, Tepich, Telá, Ucil, Kankabdzonot, Yaxuna, Santa María, Chikindzonot, Ekpedz, Tinum, Sisal, Pixoy, Tesoco, Tahmuey, Muchukux, Nabalan, Yolkobá, Sisbichén, Becanchén, Dzonotake, Pocboch, Tahcobó, Tixcankal, Labcah, Yalahan, San Fernando, Xcan, Santa María, Nolikú y Xocenpich.

Aquella guerra no tenía ejemplo: ni las mujeres, ni los niños, ni los ancianos, ni los enfermos de la raza blanca, eran perdonados. Los hombres eran empalados, desollados vivos, se les arrancaban sus miembros uno a uno ... Los niños eran recibidos en las puntas de las bayonetas y de los sables, después de haber sido arrojados por lo alto.

iLos caníbales se hubieran asustado, más bien dicho, se asustarán de aquellas escenas de estúpida y sin igual barbarie! ${ }^{36}$

No obstante, recalcó que no todo era su culpa, pues el mismo estado de barbarie en que se encontraban los hacía vulnerables a la influencia de intereses bastardos y egoístas, como el de los ingleses que desde Belice los proveían de armas y recursos, a cambio de palo de tinte y otros productos.

Enciso terminó su artículo haciendo un llamado a las autoridades para que pusieran fin a esa situación, dando a entender que para ello no había más opción que una medida radical: la guerra. ${ }^{37}$

Esto, a no dudarlo, confrontó la línea editorial de La Tribuna, fiel seguidor del general Manuel González y, por ende, preocupado por presentarlo como el inmediato héroe de la paz y de la unidad nacional. Por lo mismo no tardó en enmendarle la plana a Enciso, señalando que el único camino correcto y plausible para el país en torno a los indígenas, era el de incluirlos en la vida nacional, pues sólo así se podían lograr cambios radicales. Al efecto, el martes 21 de ese mismo mes volvió a publicar su editorial del 29 de julio pasado, y del que ya he hecho mención. ${ }^{38}$

Más, ¿cómo lograr la inserción de éstos si se mostraban reacios a ello? Díaz no pudo. El nuevo presidente lo podría lograr, si seguía el camino adecuado, que no era otro sino el de hacerlos abandonar sus parcelas improductivas, y llevarlos a las ciudades para que aprendieran un oficio y se enseñaran a leer y escribir. Ahí se les estimularía en la idea de que el trabajo era una bendición, se les premiaría si realizaban labores obreras, y se les prohibiría el alcohol y la indolencia. Igual labor se podría hacer en las haciendas y en otros centros de producción, donde los patrones estuvieran comprometidos con el bien de la nación. ${ }^{39}$

En suma, según este diario los indígenas eran los inútiles de la época, a los que había que obligar a abandonar su vida comunal para que se volvieran mano de obra disponible para el desarrollo y el progreso; productivos, pues.

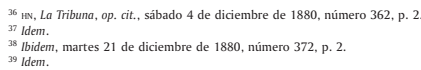


Es seguro que González estuvo de acuerdo con este planteamiento, toda vez que cuadraba muy bien con dos de sus objetivos básicos de gobierno, el de la política de conciliación con todos los sectores, y el de la modernización económica del país.

Y así pareció funcionar durante los dos primeros años de su mandato, pese a los múltiples llamados en pro de la represión, prefiriendo pactar con Inglaterra para que los colonos de ésta en Belice culminaran sus negocios con los rebeldes, en especial el del tráfico de armas. Sin embargo, su famosa Ley de Colonización y Deslinde de Terrenos Baldíos, dada en 1883, volvió a poner en boga la necesidad de la guerra para ambos bandos, pues demostró que la lucha entre la barbarie y la civilización no era otra cosa sino la lucha por la defensa de la tierra y la tradición comunal campesina, contra la redistribución de la propiedad, la circulación de la riqueza, y la explotación capitalista.

\section{Conclusiones}

Cuando llegó al poder Porfirio Díaz, en mayo de 1877, uno de los puntos básicos de su primer periodo de gobierno era el de establecer, por fin, un periodo de paz y de orden que le permitiera a México situarse entre las naciones civilizadas del mundo.

Anarquía, pobreza, rezago, división social y racial, degradación, decadencia moral, eran voces comunes que limitaban la perspectiva administrativa, por lo cual se debían atacar desde su base, que no era otra más que la de la ignorancia, la miseria y el alcoholismo.

Estos tres elementos sirvieron para justificar y explicar todo lo nefasto que ocurría en el país, desde los robos hasta las luchas indígenas contra el gobierno local y el gobierno federal, entre otras cosas.

Por lo mismo, las soluciones propuestas pretendían combatir dichos flagelos en todos los ámbitos, hasta lograr la tan decantada unidad política y social, con un régimen único que, de ser necesario, podía desembocar en el gobierno de un solo hombre, tal y como lo planteó en aquellos años el diario positivista La Libertad.

Sobre estos considerandos, no es de extrañar que la denominada guerra de castas de los mayas yucatecos de mediados del siglo xix, continuara siendo ya en el porfiriato una guerra de bárbaros y salvajes, que se atrevían a atentar contra los principales protagonistas de la civilización, sólo que ahora éstos ya no eran los blancos como sujetos físicos, sino los representantes del régimen y sus intereses.

Quizá por esto último, ya para este periodo, también, no se privilegió en la opinión pública la idea del exterminio indígena por medio de la violencia, girando el discurso respectivo sobre la conveniencia de la integración de esta raza al modelo de desarrollo nacional. La integración era la panacea, pero para lograrla los indios tenían que dejar de ser lo que se decía que eran, en palabras de casi 
todos los editorialistas: ciudadanos de segunda, cosa, instrumentos pasivos, carne de cañón, bestias de carga, jornaleros esclavos, sujetos inconscientes, perezosos, abyectos, lánguidos, viles, necios, flojos, indolentes, entre otras cosas.

Por ende, para integrarlos al buen orden y al buen camino, no había más que sacarlos de la ignorancia, educarlos en torno a las necesidades de la vida moderna, en torno a la industrialización y el trabajo productivo. Sacarlos de la ignorancia era, en suma, hacer que se olvidaran de su lengua y sus costumbres, que abandonaran sus cultivos de subsistencia, y que se integraran a la economía de mercado y a las luces de la civilización. o sea, que fueran mano de obra barata y disponible, tal como lo pedía y merecía el progreso, afirmaban.

\section{Fuentes consultadas}

\section{a) Bibliografia}

Baqueiro Preve, Serapio, Ensayo sobre las revoluciones de Yucatán desde el año de 1840 hasta 1864, Mérida, Yucatán, Universidad Autónoma de Yucatán, 1990, 4 tomos.

Bracamonte y Sosa, Pedro, Amos y sirvientes. Las haciendas de Yucatán, 1789-1860. Mérida, Yucatán, Universidad Autónoma de Yucatán, 1993, 274 pp.

__ La memoria enclaustrada. Historia indígena de Yucatán, 1750-1915, México, Centro de Investigaciones y Estudios Superiores en Antropología Social (Ciesas)/ Instituto Nacional Indigenista, 1994, 253 pp., ils. (Historia de los pueblos indígenas de México).

Bustamante, Carlos María de, Apuntes para la historia del gobierno del general D. Antonio López de Santa-Anna, desde principios de octubre de 1841 hasta 6 de diciembre de 1844, en que fue depuesto del mando por uniforme voluntad de la nación, México, Imprenta de J. M. Lara, 1845,460 pp.

González Navarro, Moisés, Raza y tierra. La guerra de castas y el henequén, 2a edición, México, El Colegio de México-Centro de Estudios Históricos, 1979, X + 392 pp.

Patch, Robert, "Descolonización, el problema agrario y los orígenes de la guerra de castas, 1812-1847", en Sociedad, estructura agraria y Estado en Yucatán, Othón Baños Ramírez, editor, Mérida, Yucatán, Universidad Autónoma de Yucatán/ Universidad de Carolina del Norte/ Universidad de Texas/ Universidad de Alabama, 1990, pp. 45-95.

Reed, Nelson, La guerra de castas de Yucatán, $8^{\text {a }}$ reimpresión, México, Era, 1993, 298 pp.

Sociedad, estructura agraria y Estado en Yucatán, Othón Baños Ramírez, editor, Mérida, Yucatán, Universidad Autónoma de Yucatán/ Universidad de Carolina del Norte/ Universidad de Texas/ Universidad de Alabama, 1990, XIII + 523 pp., ils.

\section{b) Hemerografia}

HN, El Monitor Constitucional, México, 1877.

HN, El Monitor Republicano, México, 1849-1855, 1877-1881.

HN, El Ómnibus, México, 1853.

HN, El Republicano, México, 1847.

HN, El Republicano, México, 1879-1880.

HN, El Siglo Diez y Nueve, México, 1849, 1877-1881. 
HN, La Internacional, México, 1878.

HN, La Libertad, México, 1878-1881.

hN, La Patria, México, 1879-1880.

HN, La República, México, 1880-1881.

HN, La Tribuna, México, 1879-1880. 